\title{
NEW REFINEMENTS OF TWO INEQUALITIES FOR MEANS
}

\section{JÓZSEF SÁNDOR}

Abstract. In paper [2] H. Alzer proved that the logarithmic mean of two distinct positive real numbers lies between the geometric mean and the arithmetic mean of the geometric and identric means of these numbers. Refinements of these inequalities were provided in [11]. In this note we offer refinements of a new type.

Mathematics subject classification (2010): 26D05, 26D15, 26D99.

Keywords and phrases: means of two arguments, inequalities for means, trigonometric inequalities.

\section{REFERENCES}

[1] H. AlZER, Ungleichungen für Mittelwerte, Arch. Math. (Basel), 47 (1986), 422-426.

[2] H. Alzer, Two inequalities for means, C. R. Math. Rep. Acad. Sci. Canada, 9 (1987), 11-16.

[3] H. Alzer AND S.-L. QIU, Inequalities for means in two variables, Arch. Math., 80 (2003), 201-215.

[4] B. C. CARLSOn, The logarithmic mean, Amer. Math. Monthly, 79 (1972), 615-618.

[5] E. Neuman AND J. SÁNDOR, Companion inequalities for certain bivariate means, Appl. Anal. Discr. Math., 3 (2009), 46-51.

[6] G. Pólya AND G. SZEGö, Isoperimetric inequalities in mathematical physics, Princeton Univ. Press, 1951.

[7] J. SÁNDoR, On the identric and logarithmic means, Aequationes Math., 40 (1990), 261-270.

[8] J. SÁNDOR, A note on some inequalities for means, Arch. Math. (Basel), 56 (1991), 471-473.

[9] J. SÁNDOR, On certain identities for means, Studia Univ. Babeş-Bolyai, Math., 38 (1993), 7-14.

[10] J. SÁNDOR, On certain inequalities for means, II, J. Math. Anal. Appl., 199 (1996), 629-635.

[11] J. SÁNDOR, On refinements of certain inequalities for means, Arch. Math. (Brno), 31 (1995), 279282.

[12] J. SÁNDOR AND I. RASA, Inequalities for certain means in two arguments, Nieuw Arch. Wisk., 15 (1997), 51-55.

[13] J. SÁNDOR, On certain new means and their Ky Fan type inequalities, Southeast Asian Bull. Math., 30 (2003), 99-106.

[14] J. SÁNDOR, On Huygens' inequalities and the theory of means, Int. J. Math. Math. Sci., vol. 2012, Article ID 597490, 9 pages, (2012), doi: 10.1155/2012/597490.

[15] H. J. Seiffert, Comment to Problem 1365, Math. Mag., 65 (1992), 356. 